\title{
Genome dynamics of Bartonella grahamii in micro-populations of woodland rodents
}

\author{
Eva C Berglund', Christian Ehrenborg², Olga Vinnere Pettersson ${ }^{1,3}$, Fredrik Granberg ${ }^{1}$, Kristina Näslund ${ }^{1}$, \\ Martin Holmberg ${ }^{2,4}$, Siv GE Andersson ${ }^{1 *}$
}

\begin{abstract}
Background: Rodents represent a high-risk reservoir for the emergence of new human pathogens. The recent completion of the $2.3 \mathrm{Mb}$ genome of Bartonella grahamii, one of the most prevalent blood-borne bacteria in wild rodents, revealed a higher abundance of genes for host-cell interaction systems than in the genomes of closely related human pathogens. The sequence variability within the global B. grahamii population was recently investigated by multi locus sequence typing, but no study on the variability of putative host-cell interaction systems has been performed.

Results: To study the population dynamics of B. grahamii, we analyzed the genomic diversity on a whole-genome scale of 27 B. grahamii strains isolated from four different species of wild rodents in three geographic locations separated by less than $30 \mathrm{~km}$. Even using highly variable spacer regions, only 3 sequence types were identified. This low sequence diversity contrasted with a high variability in genome content. Microarray comparative genome hybridizations identified genes for outer surface proteins, including a repeated region containing the fha gene for filamentous hemaggluttinin and a plasmid that encodes a type IV secretion system, as the most variable. The estimated generation times in liquid culture medium for a subset of strains ranged from 5 to 22 hours, but did not correlate with sequence type or presence/absence patterns of the fha gene or the plasmid.

Conclusion: Our study has revealed a geographic microstructure of B. grahamii in wild rodents. Despite nearidentity in nucleotide sequence, major differences were observed in gene presence/absence patterns that did not segregate with host species. This suggests that genetically similar strains can infect a range of different hosts.
\end{abstract}

\section{Background}

Emerging infectious diseases have increased significantly during recent decades, with major implications for human health and global economy [1]. A majority has been caused by bacteria, and many of these are zoonotic, i.e. they are accidentally transmitted to humans from other animal reservoirs in which they do not cause disease [1]. Bacteria of the genus Bartonella represent an excellent model system for studies of host adaptation patterns in zoonotic agents. Bartonella infect the red blood cells of a wide variety of mammals, and are transmitted among hosts by blood-sucking arthropods. The genus contains two recognized human-specific pathogens, Bartonella bacilliformis and Bartonella quintana, the causative agents of Carrion's disease and trench

\footnotetext{
* Correspondence: Siv.andersson@ebc.uu.se
'Department of Moleculcar Evolution, Norbyvägen 18C, S-752 36 Uppsala,

* Correspondence: Siv.andersson@ebc.uu.se
${ }^{1}$ Department of Moleculcar Evolution, Norbyvägen 18C, S-752 36 Uppsala, Sweden
}

(c) 2010 Berglund et al; licensee BioMed Central Ltd. This is an Open Access article distributed under the terms of the Creative Commons Attribution License (http://creativecommons.org/licenses/by/2.0), which permits unrestricted use, distribution, and reproduction in any medium, provided the original work is properly cited. adapted to felines but can incidentally infect humans, manifested as cat-scratch disease. Recently, an increasing number of Bartonella species with natural animal reservoirs have been associated with disease manifestations in humans [2].

Rodent-associated Bartonella are particularly attractive for studies of emerging infectious diseases, given the abundance of rodents in nature, their importance as a reservoir for infectious diseases [3] and the observation that they carry several pathogenic Bartonella species [4-9]. Field studies in many different countries have shown that Bartonella is present in most rodent populations, with conflicting results regarding host specificity [10-18]. These studies have revealed that Bartonella grahamii is one of the most prevalent Bartonella species in wild rodents. B. grahamii infects many species of mice and voles, is transmitted by the rodent flea 
Ctenophthalmus nobili [19] and has been associated with two reported cases of human disease $[5,6]$.

The genome of B. grahamii strain as4aup, isolated from a wood mouse in Sweden, was recently sequenced and found to consist of a $2.3 \mathrm{Mb}$ circular chromosome and a $28 \mathrm{~kb}$ plasmid, pBGR3 [20]. This genome is slightly smaller than the $2.6 \mathrm{Mb}$ genome of the closely related rat-associated species Bartonella tribocorum [21], but larger than the genomes of the three major human pathogens [22] (TIGR, unpublished). Sixteen genomic islands (BgGI 1-16), containing many genes for type IV and $\mathrm{V}$ secretion systems and phage genes, were identified in B. grahamii by comparison to other published Bartonella genomes [20]. Many of these genes are also present in genomic islands in $B$. henselae, albeit in lower copy numbers. Comparative microarray hybridizations of a global collection of $B$. henselae strains and one strain of its close relative Bartonella koehlerae, showed that genomic islands have been lost independently from different lineages [23,24]. Pulsed-field gel electrophoresis of the $B$. henselae strains revealed numerous rearrangements across the terminus of replication with breakpoints in regions encompassing the genomic islands [23]. In addition to these genome-scale analyses, the intra-species diversity has been studied by multi locus sequence typing (MLST) or sequencing of variable spacer regions (MST) in B. henselae, B. quintana and B. grahamii [23,25-29].

MLST schemes have been developed for all major human pathogens, and it has been the standard technique for classification of bacterial isolates [30,31]. However, while being useful for inferring the population structure, MLST only rarely correlates with virulence properties [32]. In contrast, microarray-based studies offer the opportunity to analyze the complete genome of closely related strains, and have been applied to study the diversity and the difference in virulence properties of many bacterial pathogens [33]. For both types of analysis, the standard has been to include a diverse set of strains, often collected at different time points in different parts of the world. While this strategy does well in grasping as much variability as possible, it gives a very limited understanding of the mechanisms and rates whereby hyper-variable sequences evolve, and of the environmental factors influencing these processes.

In this study, we have used a collection of B. grahamii strains isolated from wild rodents in three adjacent but non-contiguous geographic areas to analyze the genome content and the geographic microstructure of natural bacterial populations. The results revealed a geographic pattern of these strains, with few SNPs contrasting with dramatic variability in genome structure and repertoire of secretion systems.

\section{Results}

We have analyzed 27 B. grahamii isolates collected from three geographic sites, separated by circa $30 \mathrm{~km}$, in central Sweden (Table 1) [17]. Fourteen isolates were sampled in Håtunaholm, nine in Kumla and four in Ålbo. Sixteen were obtained from yellow-necked mice (Apodemus flavicollis), five from each of wood mice (Apodemus sylvaticus) and bank voles (Myodes glareolus), and one from a house mouse (Mus musculus). The prevalence of B. grahamii in the 236 captured rodents ranged between $8-16 \%$ among sites, and 6-20\% among host species [17].

\section{Few sequence polymorphisms in geographically} adjacent $B$. grahamii populations

Partial sequencing of four housekeeping genes ( $\mathrm{glt} A$, fts $Z$, batR and $c y c K)$ revealed only a single polymorphism,

Table 1 Host, geographic origin, allelic variants and ST of the 27 B. grahamii strains analyzed

\begin{tabular}{|c|c|c|c|c|c|c|c|}
\hline \multirow[t]{2}{*}{ Strain } & \multirow[t]{2}{*}{ Host } & \multirow[t]{2}{*}{ Origin $^{a}$} & \multicolumn{4}{|c|}{ Allelic variant ${ }^{b}$} & \multirow[t]{2}{*}{ ST } \\
\hline & & & 4 & 7 & 8 & 15 & \\
\hline mm3up & M. musculus & Håtunaholm & 1 & 1 & 1 & 1 & 1 \\
\hline as4aup ${ }^{c}$ & A. sylvaticus & Håtunaholm & 1 & 1 & 1 & 1 & 1 \\
\hline as4bup & A. sylvaticus & Håtunaholm & 1 & 1 & 1 & 1 & 1 \\
\hline af9up & A. flavicollis & Håtunaholm & 1 & 1 & 1 & 1 & 1 \\
\hline af30up & A. flavicollis & Håtunaholm & 1 & 1 & 1 & 1 & 1 \\
\hline af43up & A. flavicollis & Håtunaholm & 1 & 1 & 1 & 1 & 1 \\
\hline af47up & A. flavicollis & Håtunaholm & 1 & 1 & 1 & 1 & 1 \\
\hline af50up & A. flavicollis & Håtunaholm & 1 & 1 & 1 & 1 & 1 \\
\hline cg60up & M. glareolus ${ }^{d}$ & Håtunaholm & 1 & 1 & 1 & 1 & 1 \\
\hline cg64up & M. glareolus & Håtunaholm & 1 & 1 & 1 & 1 & 1 \\
\hline af66up & A. flavicollis & Håtunaholm & 1 & 1 & 1 & 1 & 1 \\
\hline af68up & A. flavicollis & Håtunaholm & 1 & 1 & 1 & 1 & 1 \\
\hline cg90up & M. glareolus & Håtunaholm & 1 & 1 & 1 & 1 & 1 \\
\hline af115up & A. flavicollis & Kumla & 1 & 1 & 1 & 1 & 1 \\
\hline cg120up & M. glareolus & Kumla & 2 & 2 & 2 & 2 & 2 \\
\hline as134up & A. sylvaticus & Kumla & 2 & 2 & 1 & 2 & 3 \\
\hline af140up & A. flavicollis & Kumla & 2 & 2 & 2 & 2 & 2 \\
\hline af144up & A. flavicollis & Kumla & 2 & 2 & 2 & 2 & 2 \\
\hline cg147up & M. glareolus & Kumla & 1 & 1 & 1 & 1 & 1 \\
\hline af156up & A. flavicollis & Håtunaholm & 1 & 1 & 1 & 1 & 1 \\
\hline af163up & A. flavicollis & Kumla & 2 & 2 & 2 & 2 & 2 \\
\hline af164up & A. flavicollis & Kumla & 2 & 2 & 2 & 2 & 2 \\
\hline af165up & A. flavicollis & Kumla & 2 & 2 & 2 & 2 & 2 \\
\hline af206up & A. flavicollis & Ålbo & 2 & 2 & 1 & 2 & 3 \\
\hline as211up & A. sylvaticus & Ålbo & 2 & 2 & 2 & 2 & 2 \\
\hline as224up & A. sylvaticus & Ålbo & 2 & 2 & 2 & 2 & 2 \\
\hline af233up & A. flavicollis & Ålbo & 2 & 2 & 1 & 2 & 3 \\
\hline
\end{tabular}

${ }^{\mathrm{a} A}$ map of the sampling sites is shown in Figure 5.

${ }^{b}$ Loci are numbered as shown in Table 2. Only loci with polymorphisms are shown.

${ }^{c} B$. grahamii as4aup is the sequenced strain. Strains as4aup and as4bup are different isolates from the same host.

${ }^{\mathrm{d}}$ Myodes glareolus was formerly called Clethrionomys glareolus. 
Table 2 Characteristics of the sequenced loci and primers used for PCR

\begin{tabular}{|c|c|c|c|c|}
\hline No. & Locus $^{a}$ & Position $^{b}$ and name or sequence $\left(5^{\prime}-3^{\prime}\right)$ of primers & Size $(b p)^{c}$ & No. of alleles ${ }^{d}$ \\
\hline \multirow[t]{2}{*}{1} & Bgr_05150 (cycK) & 622901 GCGCTGCTTACTTITTCCC & 580 & 1 \\
\hline & & 623480 TCTITCCCCATAGATCCGC & & \\
\hline \multirow[t]{2}{*}{2} & Bgr_00610 (batR) & 82636 CAATGGTGCGATCATCTACG & 535 & 1 \\
\hline & & 83190 CGTCTITATCTTITGCGCTTG & & \\
\hline \multirow[t]{2}{*}{3} & Bgr_07230 (g/tA) & 872963 BhCS.1137n [61] & 1039 & 1 \\
\hline & & 874001 CS140f [60] & & \\
\hline \multirow[t]{2}{*}{4} & Bgr_13910 (ftsZ) & 1557200 Bh ftsZ 1754.n [66] & 817 & $2(1)$ \\
\hline & & 1558016 Bh ftsZ 965.p [66] & & \\
\hline \multirow[t]{2}{*}{5} & Bgr_00430 & 61980 ATGCACAGCTTTCTGGTCG & 590 & 1 \\
\hline & & 62569 TCCTGCAATAAAACCATTTGC & & \\
\hline \multirow[t]{2}{*}{6} & Bgr_02350 (phoH) & 334448 ATCAAAACAACTTGGCTCGG & $692(158)$ & 1 \\
\hline & Bgr_02360 & 335139 TTCAGGCGATTTCATTGTAGG & & \\
\hline \multirow[t]{2}{*}{7} & Bgr_03900 (aldA) & 473807 TGTITTCCATITITGAAACGC & $725(469)$ & $2(1)$ \\
\hline & Bgr_03910 (ftsK1) & 474531 CTTCTCTTGATGCACCTTTCG & & \\
\hline \multirow[t]{2}{*}{8} & Bgr_05600 (cspA) & 679952 TGAATCCGAAACCTITTGTTG & $617(245)$ & $2(1)$ \\
\hline & Bgr_05610 (carB) & 680568 TTGGCTTITCTGTTGTCGC & & \\
\hline \multirow[t]{2}{*}{9} & Bgr_06060 (pssA) & 734202 TAGGCGCTCTTGGTTTGG & $727(70)$ & 1 \\
\hline & Bgr_06070 & 734928 TGGACGAGCCATTCTGTTATC & & \\
\hline \multirow[t]{2}{*}{10} & Bgr_06380 (uvrC) & 776004 CAATCATCCGGTAAACCCC & 768 (397) & 1 \\
\hline & Bgr_06390 & 776771 TGAAATGCGTATCCGAAAAAG & & \\
\hline \multirow[t]{2}{*}{11} & Bgr_11560 (maeB2) & 1305872 TITCGTGATCGTGTITTCC & $723(189)$ & 1 \\
\hline & Bgr_11570 (acpP2) & 1306594 GCCTGTITTAAGGCAACGAG & & \\
\hline \multirow[t]{2}{*}{12} & Bgr_15900 (asd) & 1810101 CTCCGCGATGCTCCC & $666(281)$ & 1 \\
\hline & Bgr_15910 & 1810766 AAATCCTTCGCCCAAAGC & & \\
\hline \multirow[t]{2}{*}{13} & Bgr_17890 & 2061896 CAACATTAGGGGGATTGGG & $592(245)$ & 1 \\
\hline & Bgr_17900 (dut) & 2062487 AGCCGTTGCGTAGTGAGG & & \\
\hline \multirow[t]{2}{*}{14} & Bgr_18510 (pgk) & 2129539 ACCCCATCACTGCTTCCTC & $605(514)$ & 1 \\
\hline & Bgr_18520 (gap) & 2130143 CGCGTITTGGTTTGGTATG & & \\
\hline \multirow[t]{2}{*}{15} & Bgr_19030 (ftsK2) & 2203018 CAATAAGACGCGAACCTTGAG & $880(723)$ & $2(2)$ \\
\hline & Bgr_19040 & 2203897 TCCCCCTGCAATGAGAAG & & \\
\hline \multirow[t]{2}{*}{16} & Bgr_19460 (dnaJ2) & 2239347 GCAAAGATTCGCTCTGGAAC & $708(201)$ & 1 \\
\hline & Bgr_19470 (cobS) & 2240054 ATAGCCAGAAACCATCACACG & & \\
\hline \multirow[t]{2}{*}{17} & Bgr_19730 & 2273643 CAAGGATTTCGTGCCCC & $811(144)$ & 1 \\
\hline & Bgr_19740 & 2274453 TTATGTTCGCGGTTGTTCTC & & \\
\hline
\end{tabular}

a The locus_tag and gene name, if any, for the sequenced regions in B. grahamii as4aup. For intergenic regions, both the upstream and the downstream genes are shown.

${ }^{\mathrm{b}} \mathrm{Genomic}$ positions of primers refer to the B. grahamii as4aup genome.

c Size of the total PCR product refer to the B. grahamii as4aup genome. Within parenthesis is the size of the spacer region, if any.

${ }^{\mathrm{d}}$ Within parenthesis is the number of variable sites.

located in ftsZ (Table 1, Table 2). To further differentiate the strains, we sequenced 13 loci expected to be more variable (Table 2), most of which correspond to intergenic regions that were successfully used for typing of $B$. henselae strains $[28,29]$. Polymorphisms were observed in only three of these regions (Table 1). In total, there were 5 SNPs in the $12 \mathrm{~kb}$ alignment, with three distinct sequence types (STs). We observed no sign of host specificity, for example the ST1-strains were sampled from all four host species (Table 1). In contrast, the results indicate some degree of geographic pattern, with all strains from Håtunaholm belonging to ST1, together with strains af115up and cg147up from Kumla. ST2 and ST3 were present in both Kumla and Ålbo.

\section{Differences in gene repertoires for type IV and type $\mathrm{V}$ secretion systems}

We screened for gene content variations using comparative genome hybridizations ( $\mathrm{CGH}$ ) to a microarray covering $96 \%$ of the genes in B. grahamii as4aup [20]. The results suggested that all ST1-strains have a virtually identical gene content (Figure 1), with the limitation that possible extra genes cannot be detected with CGH. All ST2 and ST3-strains displayed decreased microarray 


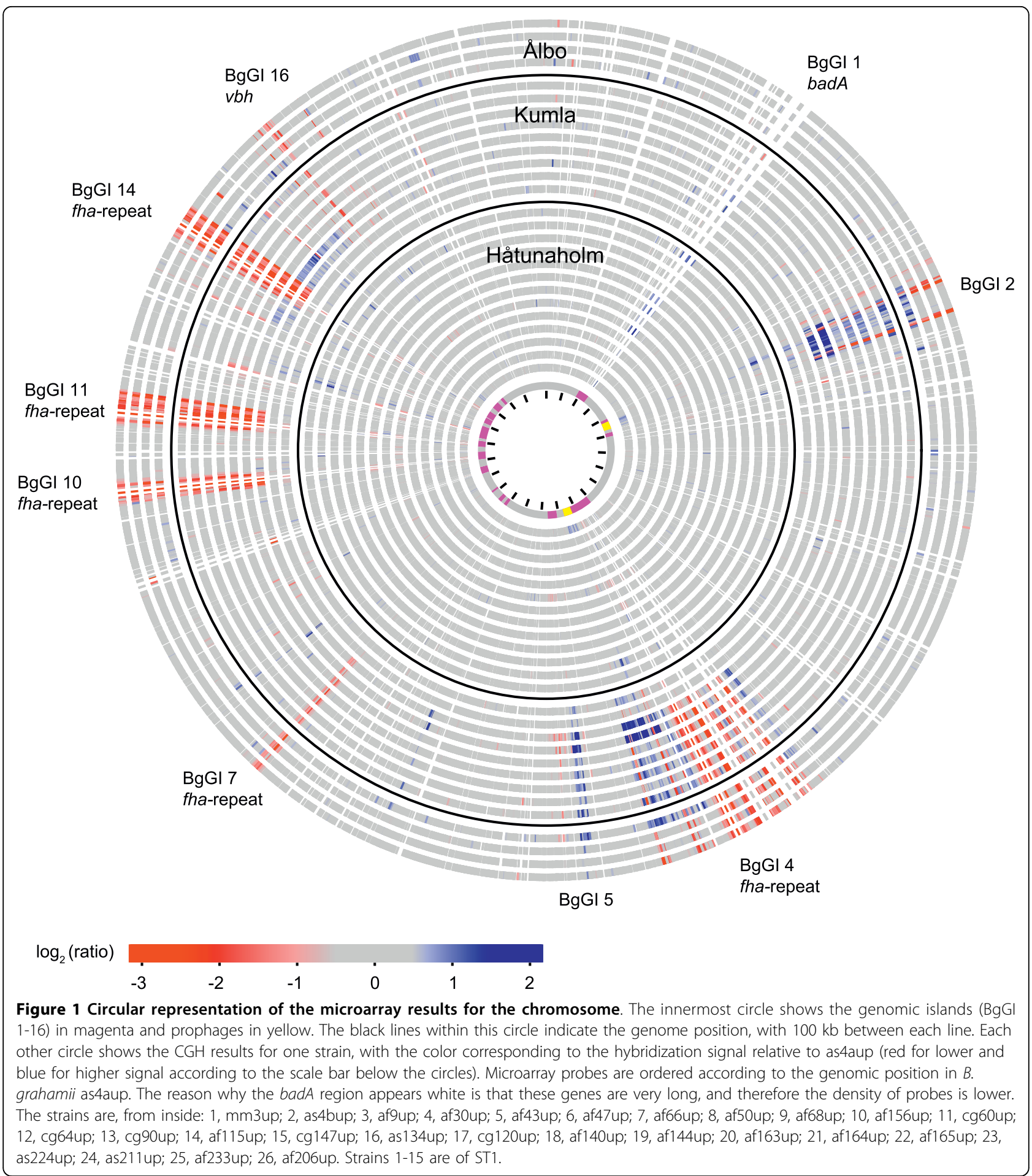

signal in comparison to the reference strain in the socalled fha-repeat, which is present in 5 genomic islands in the sequenced genome [20]. The fha/hec operon codes for a two-partner type V secretion system (T5SS), where the hec gene product probably assists in the secretion of filamentous hemagglutinin (FHA). In addition, the $f$ ha-repeat contains a number of putative virulence genes and phage genes [20].

The lower microarray signal in the $f$ ha-repeat can be due to a complete loss of these genes, a lower copy number or a high sequence divergence compared to the reference strain. Given the few identified SNPs and the 
observation that several other rapidly evolving genes, e.g. $\operatorname{bad} A$, did not show any indications of low signal, it is unlikely that the weak signal in the fha-repeat is due to sequence divergence. Attempts to amplify different fha genes by PCR using several sets of primers, all of which were tested successfully in the sequenced strain, resulted in one single PCR product in strain af140up and no products in strains af165up or as211up (see Additional file 1). Thus, all ST2 and ST3-strains are likely to have few or no copies of these genes.

In contrast, several strains displayed a relative increase in hybridization signal in the region containing the multicopy badA T5SS genes (Figure 1). BadA is a trimeric autotransporter that is essential for adhesion to host cells and bloodstream infection in Bartonella species [21,34-37]. Since the badA region is already much longer in B. grahamii than in any other sequenced Bartonella genome [20], the finding that some strains seem to have additional copies of this gene was unexpected. Variability was also observed in one of the type IV secretion systems (T4SS), namely the plasmid-encoded $v b h$ T4SS (Figure 2). The entire plasmid appeared to be absent from the strains af206up (ST2) and as211up (ST3) from Ålbo (Figure 2).

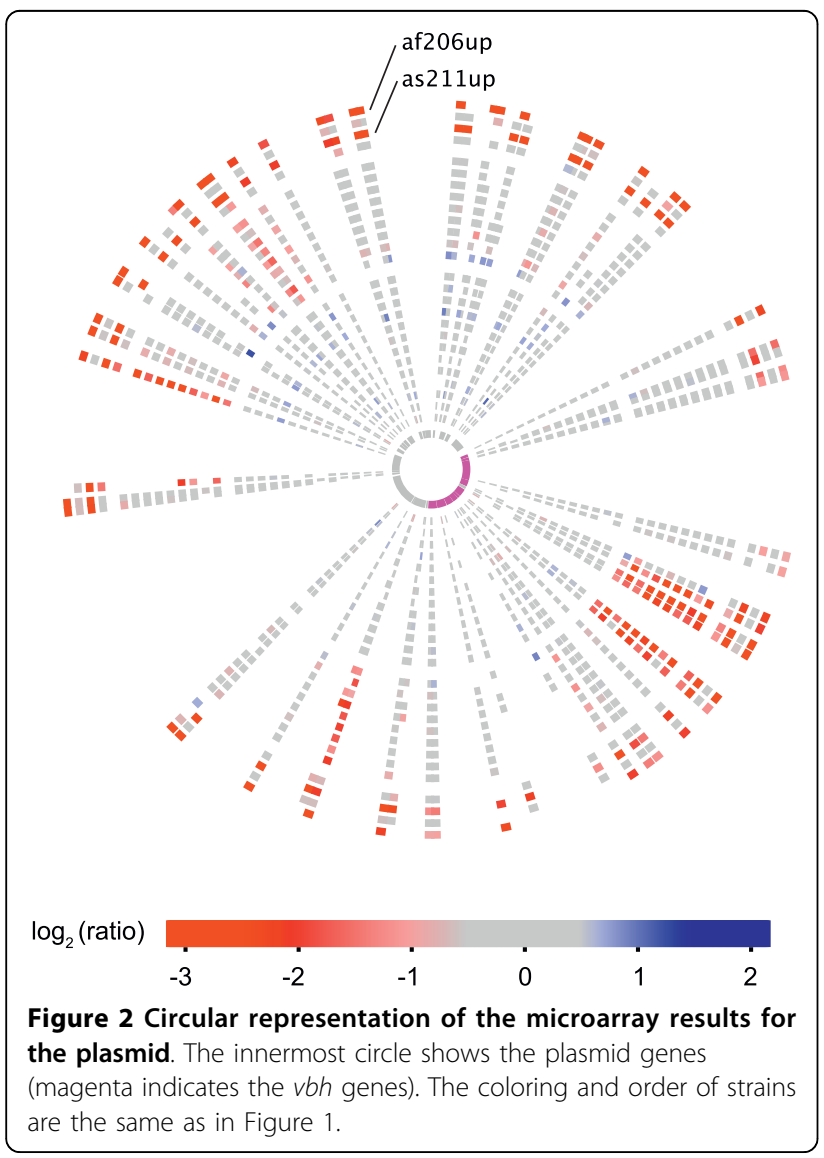

The ST2 and ST3-strains also displayed reduced hybridization signals in genes for two families of hypothetical proteins that are repeated in the genomes of B. grahamii and B. tribocorum, but have not been identified in any other sequenced Bartonella genome [20]. The first family (e.g. Bgr_15790) is present in a total of 17 copies in the sequenced strain, located adjacent to some of the fha genes. Homologs have mainly been identified in Gamma-proteobacteria, e.g. in a genomic island in Photorhabdus luminescens, in Pseudomonas syringae and Listeria monocytogenes, in one single copy in each genome. The second family (e.g. Bgr_18020) is present in 6 copies in the sequenced strain, located between $v b l 5$ and $v b l 6$ in the chromosomal $v b h$ gene cluster in BgGI 16 and on pBGR3, as well as shortly upstream of the chromosomal virB system. No homologs to this gene have been found in other genera. The remaining variability is mostly due to phages, and includes loss/divergence of single phage genes, replication of complete prophages in BgGI 2 and BgGI 4 and putatively phage-derived bi-directional runoff replication around BgGI 15, in line with previous observations [20] (Figure 1).

\section{Genome structure diversity}

Pulsed-field gel electrophoresis (PFGE) with the NotI enzyme revealed four restriction patterns in 20 representative strains and a relatively homogenous genome size of the isolates (Figure 3). One pattern was shared by all ST1strains, two were unique to three strains from Kumla and Allbo, respectively, and the last was shared between the remaining strains from Kumla and Ålbo. This result suggests some degree of correlation between genome structure and geographic origin. However, one of the restriction sites for the largest NotI band is located very close to the terminus of replication (Figure 4), and rearrangements around the terminus may thus have escaped detection. Therefore, we also employed the SgfI enzyme, which has more restriction sites than NotI in the sequenced genome of $B$. grahamii strain as4aup. With this enzyme, we observed a much greater diversity with 15 distinct patterns that showed no obvious correlation with geographic origin (Figure 3). This suggests that genome rearrangements occur frequently, in line with previous observations in B. henselae and B. quintana [23,27].

The 490 and $610 \mathrm{~kb}$ fragments obtained after cleavage of the sequenced strain with the SgfI enzyme were found to be the least conserved in the other strains (Figure 3). Both these bands contain one copy of the main prophage (Figure 4). The $490 \mathrm{~kb}$ band also contains several copies of the fha-repeat in BgGI 4 and some additional phage genes. Rearrangements within and across duplicated genes in these islands as well as across the terminus of replication could explain the variability observed after digestion with 
the SgfI enzyme. The other copies of the fha-repeat are located in BgGI 7, BgGI 10, BgGI 11 and BgGI 14. The three latter are encompassed in the $760 \mathrm{~kb}$ fragment of the Sgfl digest and in the $120 \mathrm{~kb}$ and $200 \mathrm{~kb}$ bands of the NotI digest of strain as4aup. It is interesting to note that the $120 \mathrm{~kb}$ and $200 \mathrm{~kb}$ bands are identical in size in all ST1 strains that contain the fha-repeat but differ in the ST2 and ST3-strains, which have no or fewer copies of these genes.

\section{Genomotypes do not have a random geographical distribution}

We defined the genomotype based on the ST and the two major gene content variations: presence/absence of the fha-repeat and presence/absence of the plasmid, where absence also includes cases of lower copy number. Figure 5 summarizes the distribution of the genomotypes across geographical sites and the rodent hosts associated with each type. The most striking result is that only one genomotype was recovered from Håtunaholm (type I, which is of ST1 and harbors both the fharepeat and the plasmid), although these isolates were obtained from all four different rodent host species. Genomotype I was also present in two isolates from Kumla, while absent in Ålbo. A more diverse set of isolates was identified in Kumla and Ålbo with three and four genomotypes, respectively. The fha-repeat displayed low signal in all ST2 and ST3-strains, suggesting that it 


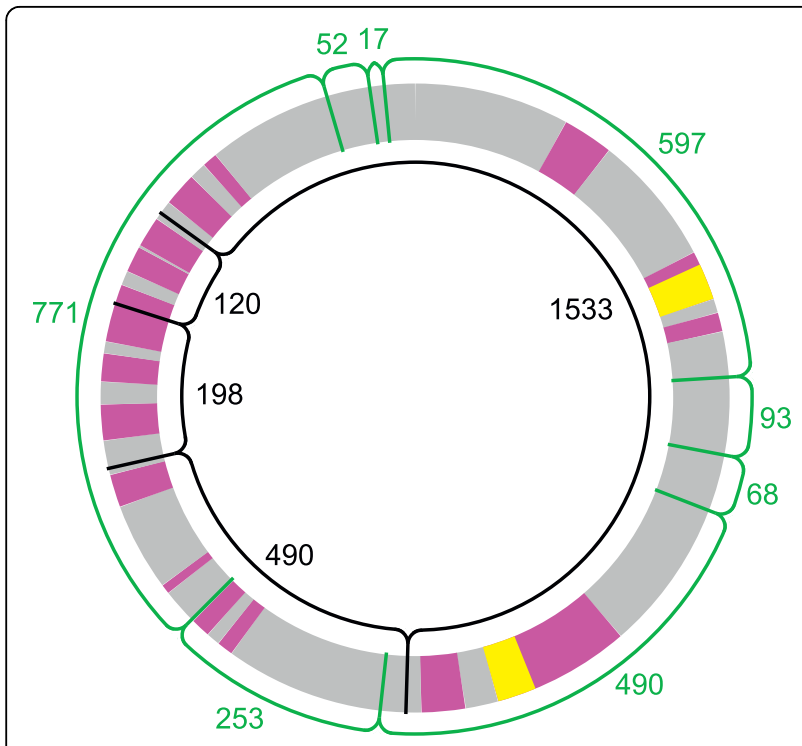

Figure 4 Predicted restriction sites of Notl and Sgfl in $B$. grahamii as4aup. The circle represents the genome of $B$. grahamii strain as4aup, with genomic islands in magenta and prophages in yellow. Restriction sites are shown in black (Notl) and green (Sgfl). The predicted size of each band is shown inside the circle for Notl and outside for Sgfl.

was lost or gained only once. In contrast, the plasmid was variably present in both ST2 and ST3 and is likely to have experienced a minimum of two gain/loss events, unless one of the variants is the result of a recombination event.

\section{B. grahamii strains exhibit large differences in growth rate in liquid culture}

In order to compare genomic differences to phenotypic traits, we selected five representative strains and studied their growth in liquid culture for ten days (Figure 6). We observed large differences in growth rate, with the only strain isolated from Mus musculus (mm3up) growing significantly slower than the others and reaching a lower maximal optical density (Table 3). The maximal generation times, ranging from approximately 5 (as206up) to 22 (mm3up) hours, did not correlate with $\mathrm{ST}$, presence/absence of the fha-repeat or presence/ absence of the plasmid. We also performed aggregation assays for three strains (as4aup, af165up and af206up), but observed no significant differences between them (data not shown).

\section{Discussion}

In this study, we have analyzed the genomic diversity of B. grahamii from wild rodents in three adjacent geographic areas in central Sweden. To our knowledge, this is the first genome-scale analysis of bacterial populations from wild animals in a geographically restricted area.
Since these rodents typically have a home area of less than 1 hectare, and seldom migrate distances longer than $30 \mathrm{~km}[38,39]$, genetic exchange between the three sites is expected to be limited. Indeed, we observed a geographic pattern in the distribution of genomotypes, showing that microstructures of bacterial populations inhabiting hosts with limited migration are visible also in the comparison of closely located sites. One of the sites, Håtunaholm, displayed a lower degree of genomic diversity than the others, with all isolates being of the same genomotype. In contrast, the presence of strains of ST2 and ST3 in both Kumla and Allbo suggests that exchange has occurred at least twice between these regions. A possible reason for the clonal population in Håtunaholm is that this site is surrounded by water and only connected to Kumla and Ålbo by a narrow piece of land, where the small town Bålsta is situated (Figure 5). This environmental barrier is likely to restrict the genetic flow by isolation of hosts and vectors. The presence of two ST1-strains in Kumla suggests that the Håtunaholm population is a recent expansion of an immigrant from the Kumla region, or that the clonal variants in Håtunaholm occasionally escape the inland seawater barriers.

Despite sequencing regions expected to be among the most variable in the genome, we observed only five SNPs in 27 strains, corresponding to only three STs. As expected, this is much less diversity than what was observed in a previous MLST analysis of a global collection of $31 \mathrm{~B}$. grahamii strains, where 10-16 variants were identified for each gene [40]. However, previous MLST analysis of 7 house-keeping genes in the likewise intracellular Borrelia lucitaiae collected from ticks on lizards in two nearby geographic areas identified 13 types in 16 isolates [41], suggesting that the low sequence diversity observed in our population is not necessarily a general feature of vector-borne bacterial populations in restricted geographic areas. Future studies of similar bacterial populations will reveal the degree of diversity that they typically display, and help elucidate the factors that govern these dynamics.

In light of the limited sequence diversity, the gene content of the studied populations was very dynamic, with the major differences being associated with the plasmid pBGR3 and the fha-repeat. Thus, gene gain and loss occur so frequently in nature that even strains sampled from the same geographic site with essentially no nucleotide sequence differences in a subset of their housekeeping genes can have major differences in gene content. This result shows that traditional MLST may not always be appropriate for inferring phenotypic or virulence properties, and illustrates the importance of a whole-genome approach when analyzing bacterial diversity. Furthermore, our results show that comparisons of 


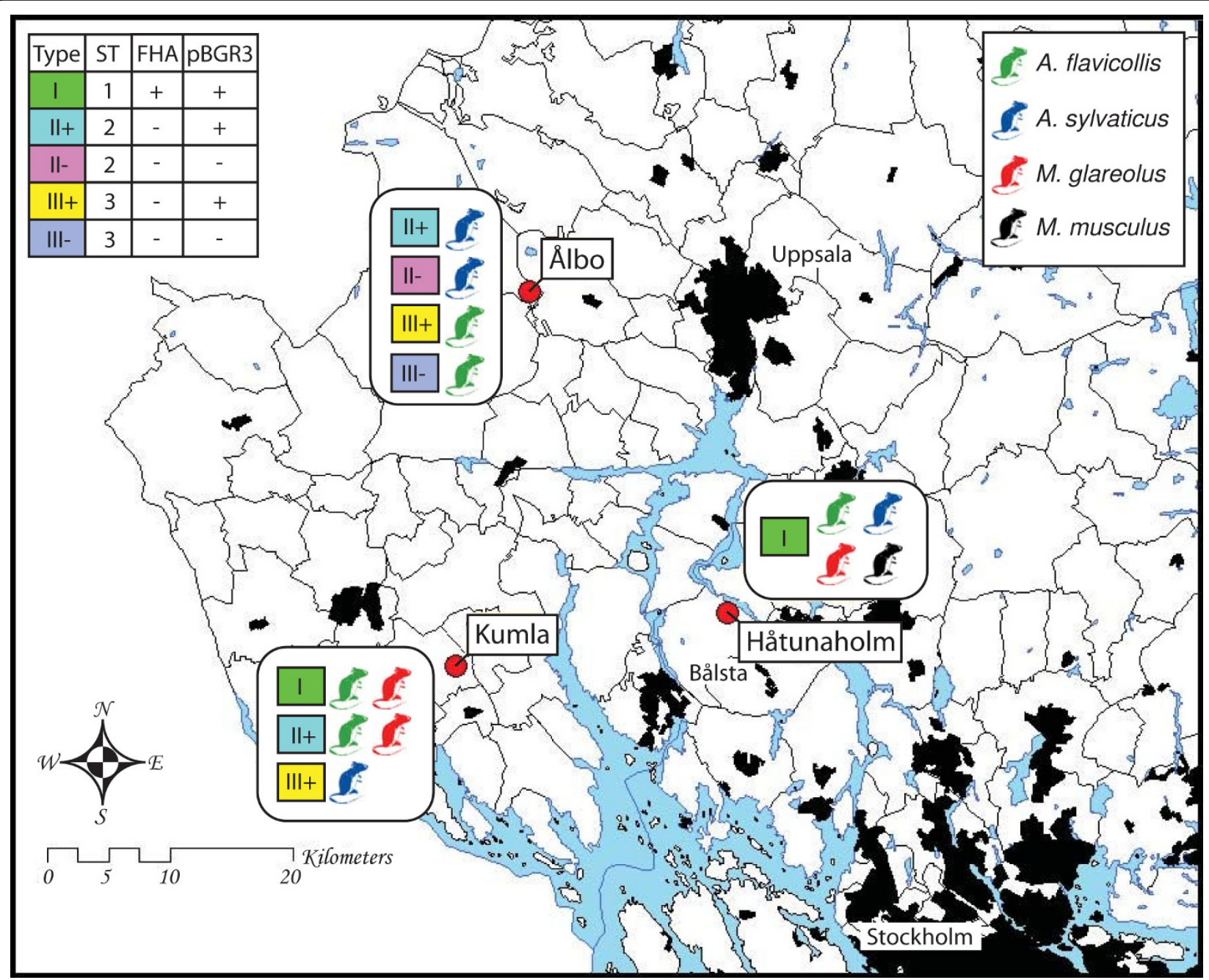

Figure 5 Distribution of genomotypes across geographic sites. The map shows the locations of the geographic sites where the rodents were collected. The definition of the genomotypes (based on sequence type, presence/absence of the fha-repeat and presence/absence of the plasmid) is shown in the upper left corner. For each genomotype at each site, the different rodent hosts associated with this particular variant are shown, color-coded according to the legend in the upper right corner.

genomic diversity in different geographic regions should be based on multiple strains from each location, since selecting only one or a few strains from each region for sequencing might easily underestimate the true genomic diversity. The real diversity could also be underestimated if there is considerable within-host heterogeneity and each host is represented by only one or a few strains. However, for B. grahamii we consider such within-host genomic diversity unlikely since a random sampling of a heterogeneous micro-population would recover more than a single genomotype from Håtunaholm.

The function of FHA is not known in Bartonella, but by homology inference to Bordetella, we assume that it acts as an adhesin and/or immunomodulator. In pathogenic Bordetella species, the fhaB/fhaC genes encode a two-partner type V secretion system, where FhaB is translocated to the cell surface with the aid of FhaC, which is homologous to Hec in Bartonella [42,43]. The mature FHA protein is required for adhesion to epithelial cells and has a role in apoptosis and immunosuppression [44-48]. The fhaB/fhaC genes are located within a well conserved single copy gene cluster in all pathogenic Bordetella species, however, several paralogs to $f$ h $B$ have been identified [49]. Comparative genome hybridizations have shown no losses of fhaB/fhaC, but occasional losses of the fhaB paralogs [50-52]. In Bordetella bronchiseptica, it was suggested that one of the FhaB paralogs (FhaS) might be involved in host-specificity [53]. Although FhaS is not required for infection, a $\Delta f h a S$ strain was out-competed by the wild type during coinfection [53]. 


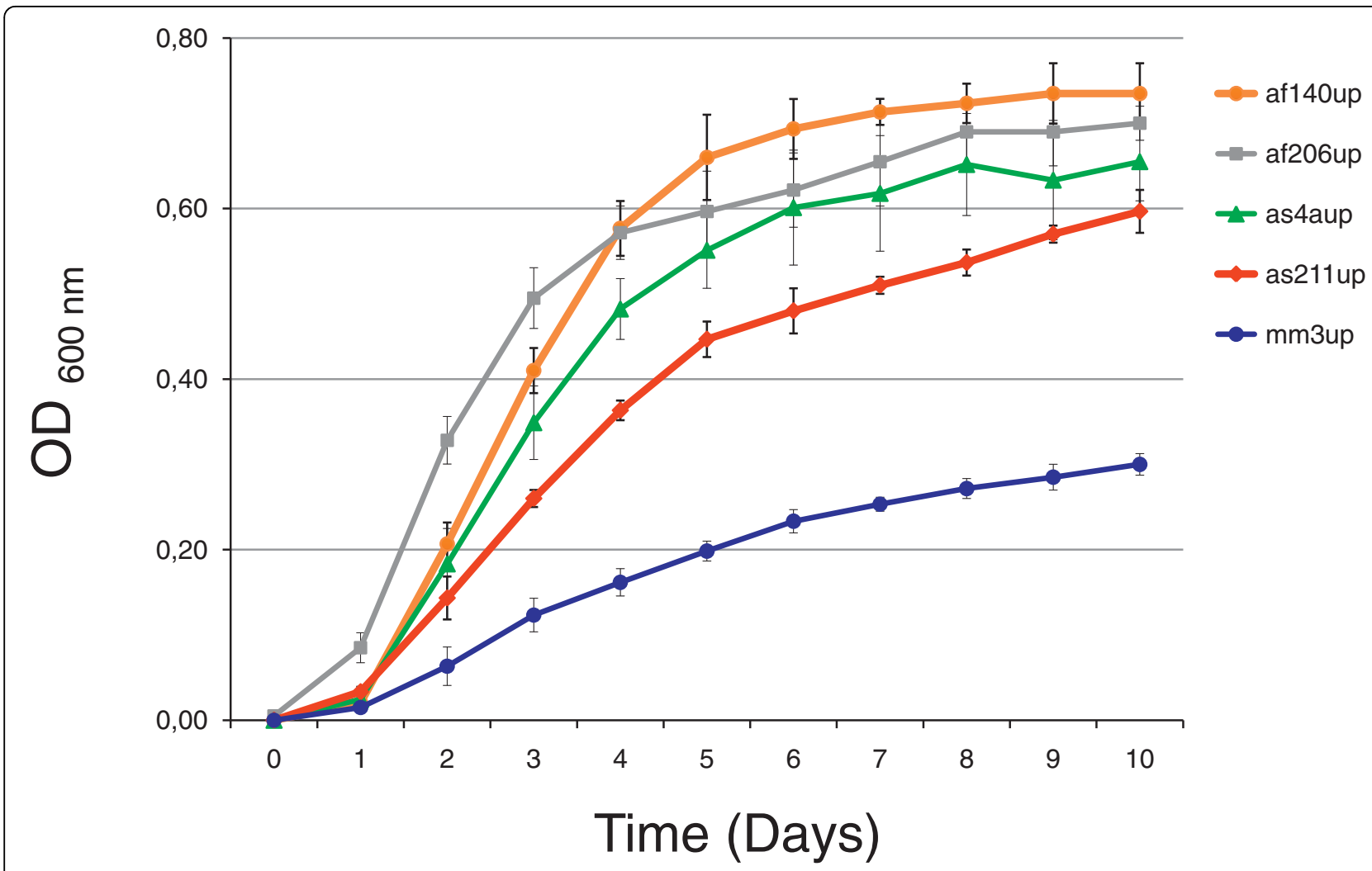

Figure 6 Growth curves of B. grahamii. Growth curves of five B. grahamii strains in supplemented Schneider's medium. Bacterial growth was determined by measuring the $\mathrm{OD}_{600}$ in triplicates at $24-\mathrm{h}$ intervals.

Table 3 Maximum growth rates in supplemented Schneider's medium

\begin{tabular}{lllll}
\hline Strain & ST & FHA & pBGR3 & Generation time (hours) \\
\hline af206up & 3 & - & - & 5.4 \\
af140up & 2 & - & + & 7.0 \\
as4aup & 1 & + & + & 8.2 \\
as211up & 2 & - & - & 11.9 \\
mm3up & 1 & + & + & 21.8 \\
\hline
\end{tabular}

One could think of a similar situation in Bartonella, namely that some of the various fha gene copies confer host specificity and/or are advantageous only under certain conditions. Such a scenario would be consistent with their location within genomic islands that have been integrated/excised multiple times independently in B. grahamii, B. henselae and B. tribocorum [20,22], and with the many cases of pseudogenization of individual fha genes. Some degree of variability was observed among strains in B. henselae although none had completely lost the fha genes [23]. In contrast, the fha genes have been lost from all strains of $B$. quintana investigated (data not shown) and are also absent from $B$. bacilliformis $[20,22]$. The absence of the fha gene in several strains and species suggests that the gene may be lost from individual Bartonella populations, both temporarily and permanently, and is therefore not essential for growth and infection per se. Indeed, we observed no significant differences in either growth rate or level of autoaggregation between strains with different copy numbers of the fha gene.

Since rodents have an adaptive immune system, shedding of surface-exposed proteins could potentially enable super-infection, i.e. a second infection of a previously infected animal. Immunity against super-infection of the same Bartonella species has indeed been demonstrated in rodent hosts [54]. Under this scenario, loss of the fha gene might be the only way to escape acquired immunity in the rodent host population. If selection for functionality is balanced by counter-selection from the host immune system, this could trigger a periodic cycle in which strains with and without fha repeatedly out-compete each other. The possibility for super-infection is likely to depend on the transmission rates, and thus the abundance of hosts and vectors. A high density of hosts and vectors will increase transmission rates, and might favor loss of fha genes from many individuals in a population. Vice versa, if hosts and 
vectors are low in abundance, super-infections will be rare and host-acquired immunity less of a problem, which might set the stage for the return of strains with fha.

The only putative host-interaction genes located on the plasmid are those encoding a $v b h$ T4SS that is closely related to the chromosomal $v b h$ system, and more distantly related to the virB system, which has been shown to be essential for infection in B. tribocorum and secrets Bartonella effector proteins into the host cell [55-57]. The plasmid also contains a set of tra genes, including the DNA binding traA, which are usually involved in conjugation. It is not known whether the $v b h$ gene cluster encodes proteins involved in host interactions or if it is only part of a conjugation system. The presence of a putative addiction module, consisting of a killer and an antidote protein, on pBGR3 (Bgr_p00250Bgr_p00260) may ensure the survival of the plasmid in the population even in the absence of selection.

The observation that the Håtunaholm strains were sampled from four different rodent species shows that B. grahamii isolates with similar gene contents are capable of infecting diverse hosts. Such a lack of host-specificity contrasts with experimental infections of the cotton rat (Sigmodon hispidus) and the white-footed mouse (Peromyscus leucopus), which indicates that Bartonella strains are only able to infect hosts that are closely related to the host from which it was originally isolated [58]. Although S. hispidus and P. leucopus belong to the same family of rodents (Cricetidae), crossinfections were not observed [58]. The rodents sampled in Håtunaholm belong to two different families, Cricetidae and Muridae, which are genetically more diverged [59], yet harbor similar B. grahamii strains. This suggests a lack of host-specificity, although minor sequence differences among strains may have gone undetected in our survey. Since the only parameter showing some correlation with the generation times was the host of isolation, it is possible that the growth rate of each strain has been optimized for its particular host. It remains to be shown, however, whether a specific isolate from Håtunaholm is actually capable of infecting both mice and voles, or if there are nucleotide sequence or expression differences in outer surface proteins that account for host specificity but were not detected in this analysis.

In the future, results on the natural genomic diversity of zoonotic bacterial populations should be analyzed in an ecological context, including data about e.g. host and vector abundance and climate, to allow correlations between genomic diversity and bacterial prevalence or seasonal variation. Our results also urge for functional characterization of the role of FHA in Bartonella, and offer an opportunity to study the infectious process of strains with observed differences in genes for surfaceexposed proteins in rodent hosts.

\section{Conclusion}

Based on studies of SNPs and gene contents by comparative microarray genome hybridization, we present an illustration of how different genomotypes of B. grahamii are distributed across nearby geographic locations. Despite a very limited number of SNPs, we observed dramatic changes in terms of genome structure and content, with the major gains/losses being a plasmid encoding a $v b h$ T4SS and a repeated region containing the fha/hec genes for a T5SS. Whereas a mixture of different genomotypes was recovered from rodents in Ålbo and Kumla, all strains isolated from rodents in Håtunaholm were identical in both ST and gene content. This suggests that environmental barriers in the form of water can lead to isolation and loss of genomic variability in host-associated bacterial populations. Neither the STs nor the gene content variability correlated with host of isolation, indicating a lack of host-specificity in these populations. However, the generation time was significantly longer for a strain isolated from $M$. musculus (more than 20 hours), than for strains isolated from Apodemus mice, only 5 to 12 hours. This might indicate growth rate optimization in response to the host cell environment. Given the variability in gene content and generation times for strains isolated from within such a small geographic region, we emphasize the importance of selecting more than a single strain for genomic and functional genomics analyses.

\section{Methods}

\section{Bacterial strains and DNA isolation}

All B. grahamii strains used in this study were isolated from wild rodents in September 1999 [17]. For production of bacterial stock suspensions, bacteria were harvested from hematin agar plates after four days and stored at $-80^{\circ} \mathrm{C}$ in a buffer containing $150 \mathrm{mM} \mathrm{NaCl}$, $50 \mathrm{mM}$ Tris (pH 7) and $11.2 \%$ glycerol. The number of viable bacteria in the frozen stocks was determined by plating serial dilutions of the suspension and calculating the number of colony forming units (CFU). DNA was extracted from bacteria grown for 5-10 days on hematin agar plates, as described previously [24].

\section{PCR amplification}

Sequence data was collected for seventeen genomic regions, using primers listed in Table 2. Primers used for PCR of $f h a$ are listed in Additional file 1. For $g l t A$ and ftsZ, PCR amplifications were performed with a Perkin-Elmer GeneAmp 9600 thermocycler using a PCR Master kit from Boehringer Mannheim Scandinavia AB 
(Bromma, Sweden). The $50 \mu \mathrm{l}$ reaction mixture consisted of the template, forward and reverse primers (10 $\mathrm{pmol} /$ primer), $25 \mu \mathrm{l}$ PCR master mix, and distilled water of PCR-grade up to $50 \mu \mathrm{l}$. The reaction conditions were $5 \mathrm{~min}$ at $95^{\circ} \mathrm{C}, 10$ cycles at $94^{\circ} \mathrm{C}$ for $20 \mathrm{~s}, 50^{\circ} \mathrm{C}$ for 1 min, $72^{\circ} \mathrm{C}$ for $90 \mathrm{~s}$, annealing temperature lowered $1^{\circ} \mathrm{C}$ per cycle until reaching $40^{\circ} \mathrm{C}$. This was followed by 40 cycles at $94^{\circ} \mathrm{C}$ for $20 \mathrm{~s}, 40^{\circ} \mathrm{C}$ for $1 \mathrm{~min}, 72^{\circ} \mathrm{C}$ for $90 \mathrm{~s}$ and a $7 \mathrm{~min}$ extension period at $72^{\circ} \mathrm{C}$. PCR products were purified with the QIAquick purification kit from QIAGEN, Inc., Chatsworth, Calif., U.S., according to the manufacturer's instructions. PCR products were sequenced with an ABI 310 Genetic Analyzer (PerkinElmer Corp., Norwalk, Conn., US). The gltA product was sequenced with primers CS443f [60] and BhCS.781p [61] in addition to the primers used for PCR. Sequencing reactions were performed using a DNA Sequencing Kit with AmpliTaq ${ }^{\circledR}$ DNA Polymerase, FS, for the BigDye ${ }^{\mathrm{m}}$ Terminator Cycle Sequencing Ready Reaction protocol (Perkin-Elmer, Applied Biosystems, Warrington, GB). Remaining PCR reactions were performed as described previously [23].

\section{Analysis of sequence data}

Sequences for $g l t A$ and $f t s Z$ were analyzed with $\mathrm{ABI}$ Prism $^{\text {nx }}$ DNA Sequencing Analysis Software Version 3.0 (PE Applied Biosystems, Foster City, CA, US) and Sequencher $^{\mathrm{rm}}$ (Gene Codes Corporation, Ann Arbor, MI, US). Remaining sequences were assembled and edited with Phred, Phrap and Consed [62-64]. The allele of the sequenced strain was named allele 1 and the combination of alleles was used to define the sequence types.

\section{Microarray comparative genome hybridizations}

Microarrays were designed and manufactured as reported previously [20] and cross-linked at $250 \mathrm{~mJ} / \mathrm{cm}^{2}$ (slides printed at the Royal Institute of Technology) or $800 \mathrm{~mJ}$ (slides printed at Uppsala University). Genomic DNA from the sequenced strain was used as reference in all hybridizations and two or three hybridizations were performed for each strain. Prehybridization, DNA labeling, hybridization, scanning and image analysis were performed as described previously [20]. The channel used for the reference strain is referred to as Ch1 and the test strain is referred to as Ch2, and spots meeting the following criteria were removed from further analysis: spots flagged as bad or not found during quantification, spots with more than $10 \%$ saturated pixels in either channel, Ch1 spot median below 2 times the Ch1 background median, less than $90 \%$ of pixels having a Ch1 intensity higher than background intensity plus one standard deviation, less than $75 \%$ of pixels having a Ch1 intensity higher than background intensity plus two standard deviations or spots having less than
70 pixels. $\mathrm{M}$-values were computed as $\log _{2}(\mathrm{Ch} 2 / \mathrm{Ch} 1)$ and normalization was performed as described previously [23]. Median M-values of all replicate spots and arrays were computed for each strain. A gene was defined as absent if the median $\mathrm{M}$-value of all probes in that gene was $\leq-2$.

\section{Pulsed-field gel electrophoresis}

Bacteria grown for 10 days were digested with $10 \mathrm{U}$ of NotI (New England Biolabs) or SgfI (Promega) restriction endonucleases. Experimental procedures for digestion were as reported previously [24]. The DNA fragments were separated in 0.9\% PFGE-grade agarose (SeaKem ${ }^{\circ}$ Gold; Cambrex Bio Science) in 0.5× TBE buffer in GenNavigator ${ }^{\circ}$ System apparatus (Amersham Biosciences) at $14^{\circ} \mathrm{C}$ and $5.6 \mathrm{~V} / \mathrm{cm}$, for a total of 65 hours. The total run was separated in six phases; switch times ramped from 5 to $150 \mathrm{~s}$. The sizes of the fragments were estimated using PFGE $\lambda$-ladder and Yeast Chromosome PFG marker (New England Biolabs).

\section{Growth curves in liquid culture}

For growth in liquid culture, frozen bacterial stocks were thawed on ice and inoculated at a concentration of approximately $10^{6} \mathrm{CFU}$ per $\mathrm{ml}$ into Schneider's insect medium (Sigma) supplemented with 10\% FBS (heat inactivated at $56^{\circ} \mathrm{C}$ for $30 \mathrm{~min}$ ) and $5 \%$ sucrose, as described by Riess et al. [65]. In addition, the medium was supplemented with $0.1 \mathrm{M}$ HEPES, to keep the $\mathrm{pH}$ near 7 . Bacterial growth was determined by measuring the optical densities at $600 \mathrm{~nm}\left(\mathrm{OD}_{600}\right)$ in triplicates at 24-h intervals. For strain as4aup, the number of CFU was determined at each time point by plating 10-fold serial dilutions. We used the formula described by Reiss et al. [65] to estimate the maximum growth rate, expressed as generation time, for each strain, assuming a similar amount of bacteria at a certain optical density as for as4aup.

\section{Aggregation assays}

Bacteria grown in liquid cultures as described above were sampled in the mid-exponential phase. The bacterial cells were centrifuged, and pellets were suspended in phosphate buffered saline (PBS) to an $\mathrm{OD}_{600}$ of 0.6. After gentle vortexing, standing tubes with $5 \mathrm{ml}$ of bacterial suspension were incubated at $35^{\circ} \mathrm{C}$, and the $\mathrm{OD}_{600}$ of the upper part of the suspensions was measured throughout time (0 min, $5 \mathrm{~min}, 15 \mathrm{~min}, 1 \mathrm{~h}, 4 \mathrm{~h}$ and $22 \mathrm{~h}$ ).

\section{Nucleotide sequence and microarray accession numbers}

The novel sequences of $f t s Z$ and three spacers have been submitted to GenBank under the accession numbers FN597604. FN597607. The microarray data have been deposited in the ArrayExpress database of the European 
Bioinformatics Institute under the accession number the accession numbers A-MEXP-1741 and A-MEXP-1576 for the array designs and E-TABM-850 for the experimental data.

\section{List of abbreviations}

MLST: multi locus sequence typing; MST: multi spacer typing; CGH: comparative genome hybridization; PFGE: pulsed-field gel electrophoresis; SNP: single nucleotide polymorphism; ST: sequence type.

\section{Additional file 1: List of primers used for PCR of fha, and PCR} results.

Click here for file

[http://www.biomedcentral.com/content/supplementary/1471-2164-11152-S1.PDF ]

\section{Acknowledgements}

We thank Kirsten Ellegaard, Anna Åsman and Marcel Verhaart for technical assistance, Magnus Lundgren for graphical work and Björn Nystedt for helpful discussions. We thank Annelie Waldén at the Royal Institute of Technology, Stockholm, Sweden, and Niclas Olsson at Uppsala University, Uppsala, Sweden, for microarray printing. This work was supported by grants to S.G.E.A. from the Swedish Research Council, the Göran Gustafsson Foundation, the Swedish Foundation for Strategic Research and the Knut and Alice Wallenberg Foundation.

\section{Author details}

'Department of Moleculcar Evolution, Norbyvägen 18C, S-752 36 Uppsala, Sweden. ${ }^{2}$ Department of Medical Sciences, Section for Infectious Diseases, Uppsala University Hospital, S-751 85 Uppsala, Sweden. ${ }^{3}$ Current address: Department of Microbiology, The Swedish Agricultural University, Uppsala, Sweden. ${ }^{4}$ Current address: Socialstyrelsen, Stockholm, Sweden.

\section{Authors' contributions}

ECB performed the microarray CGH experiments, carried out the sequence and microarray data analyses and prepared the manuscript. CE participated in the sequence analysis and drafted part of the manuscript. OVP performed the PFGE experiments. FG performed the cultivation and aggregation experiments. KN performed the cultivation and sequencing experiments. $\mathrm{MH}$ contributed strains, analyzed experimental data and helped in the design of the study. SGEA designed the study, analyzed experimental data, prepared the manuscript and coordinated the project. All authors read and approved the final manuscript.

Received: 1 November 2009 Accepted: 4 March 2010

Published: 4 March 2010

\section{References}

1. Jones KE, Patel NG, Levy MA, Storeygard A, Balk D, Gittleman JL, Daszak P: Global trends in emerging infectious diseases. Nature 2008, 451:990-993.

2. Boulouis HJ, Chang CC, Henn JB, Kasten RW, Chomel BB: Factors associated with the rapid emergence of zoonotic Bartonella infections. Vet Res 2005, 36:383-410.

3. Woolhouse ME, Gowtage-Sequeria S: Host range and emerging and reemerging pathogens. Emerg Infect Dis 2005, 11:1842-1847.

4. Daly JS, Worthington MG, Brenner DJ, Moss CW, Hollis DG, Weyant RS, Steigerwalt AG, Weaver RE, Daneshvar MI, O'Connor SP: Rochalimaea elizabethae sp. nov. isolated from a patient with endocarditis. J Clin Microbiol 1993, 31:872-881.

5. Kerkhoff FT, Bergmans AM, Zee van Der A, Rothova A: Demonstration of Bartonella grahamii DNA in ocular fluids of a patient with neuroretinitis. J Clin Microbiol 1999, 37:4034-4038.
6. Serratrice J, Rolain JM, Granel B, Ene N, Conrath J, Avierinos JF, Disdier P, Raoult D, Weiller PJ: [Bilateral retinal artery branch occlusions revealing Bartonella grahamii infection]. Rev Med Interne 2003, 24:629-630.

7. Welch DF, Carroll KC, Hofmeister EK, Persing DH, Robison DA, Steigerwalt AG, Brenner DJ: Isolation of a new subspecies, Bartonella vinsonii subsp. arupensis, from a cattle rancher: identity with isolates found in conjunction with Borrelia burgdorferi and Babesia microti among naturally infected mice. J Clin Microbiol 1999, 37:2598-2601.

8. Fenollar F, Sire S, Raoult D: Bartonella vinsonii subsp. arupensis as an agent of blood culture-negative endocarditis in a human. J Clin Microbiol 2005, 43:945-947.

9. Kosoy M, Murray M, Gilmore RD Jr, Bai Y, Gage KL: Bartonella strains from ground squirrels are identical to Bartonella washoensis isolated from a human patient. J Clin Microbiol 2003, 41:645-650.

10. Ellis BA, Regnery RL, Beati L, Bacellar F, Rood M, Glass GG, Marston E, Ksiazek TG, Jones D, Childs JE: Rats of the genus Rattus are reservoir hosts for pathogenic Bartonella species: an Old World origin for a New World disease? J Infect Dis 1999, 180:220-224.

11. Ying B, Kosoy MY, Maupin GO, Tsuchiya KR, Gage KL: Genetic and ecologic characteristics of Bartonella communities in rodents in southern China. Am J Trop Med Hyg 2002, 66:622-627.

12. Castle KT, Kosoy M, Lerdthusnee K, Phelan L, Bai Y, Gage KL, Leepitakrat W Monkanna T, Khlaimanee N, Chandranoi K, et al: Prevalence and diversity of Bartonella in rodents of northern Thailand: a comparison with Bartonella in rodents from southern China. Am J Trop Med Hyg 2004, 70:429-433.

13. Pretorius $A M$, Beati $L$, Birtles RJ: Diversity of bartonellae associated with small mammals inhabiting Free State province, South Africa. Int J Syst Evol Microbiol 2004, 54:1959-1967.

14. Jardine C, Appleyard G, Kosoy MY, McColl D, Chirino-Trejo M, Wobeser G, Leighton FA: Rodent-associated Bartonella in Saskatchewan, Canada. Vector Borne Zoonotic Dis 2005, 5:402-409.

15. Inoue K, Maruyama S, Kabeya H, Yamada N, Ohashi N, Sato Y, Yukawa M, Masuzawa T, Kawamori F, Kadosaka T, et al: Prevalence and genetic diversity of Bartonella species isolated from wild rodents in Japan. Appl Environ Microbiol 2008, 74:5086-5092.

16. Birtles RJ, Harrison TG, Molyneux DH: Grahamella in small woodland mammals in the U.K.: isolation, prevalence and host specificity. Ann Trop Med Parasitol 1994, 88:317-327.

17. Holmberg M, Mills JN, McGill S, Benjamin G, Ellis BA: Bartonella infection in sylvatic small mammals of central Sweden. Epidemiol Infect 2003, 130:149-157.

18. Engbaek K, Lawson PA: Identification of Bartonella species in rodents, shrews and cats in Denmark: detection of two B. henselae variants, one in cats and the other in the long-tailed field mouse. Apmis 2004, 112:336-341

19. Bown KJ, Bennet M, Begon M: Flea-borne Bartonella grahamii and Bartonella taylorii in bank voles. Emerg Infect Dis 2004, 10:684-687.

20. Berglund EC, Frank AC, Calteau A, Vinnere Pettersson O, Granberg F, Eriksson AS, Naslund K, Holmberg M, Lindroos H, Andersson SG: Run-off replication of host-adaptability genes is associated with gene transfer agents in the genome of mouse-infecting Bartonella grahamii. PLOS Genet 2009, 5:e1000546.

21. Saenz HL, Engel P, Stoeckli MC, Lanz C, Raddatz G, Vayssier-Taussat M, Birtles R, Schuster SC, Dehio C: Genomic analysis of Bartonella identifies type IV secretion systems as host adaptability factors. Nat Genet 2007 39:1469-1476.

22. Alsmark CM, Frank AC, Karlberg EO, Legault BA, Ardell DH, Canback B, Eriksson AS, Naslund AK, Handley SA, Huvet M, et al: The louse-borne human pathogen Bartonella quintana is a genomic derivative of the zoonotic agent Bartonella henselae. Proc Natl Acad Sci USA 2004, 101:9716-9721.

23. Lindroos H, Vinnere O, Mira A, Repsilber D, Naslund K, Andersson SG: Genome rearrangements, deletions, and amplifications in the natural population of Bartonella henselae. J Bacteriol 2006, 188:7426-7439.

24. Lindroos HL, Mira A, Repsilber D, Vinnere O, Naslund K, Dehio M, Dehio C, Andersson SG: Characterization of the genome composition of Bartonella koehlerae by microarray comparative genomic hybridization profiling. J Bacteriol 2005, 187:6155-6165. 
25. Iredell J, Blanckenberg D, Arvand M, Grauling S, Feil EJ, Birtles RJ: Characterization of the natural population of Bartonella henselae by multilocus sequence typing. J Clin Microbiol 2003, 41:5071-5079.

26. Arvand M, Feil EJ, Giladi M, Boulouis HJ, Viezens J: Multi-locus sequence typing of Bartonella henselae isolates from three continents reveals hypervirulent and feline-associated clones. PLOS ONE 2007, 2:e1346.

27. Foucault C, La Scola B, Lindroos H, Andersson SG, Raoult D: Multispacer typing technique for sequence-based typing of Bartonella quintana. J Clin Microbiol 2005, 43:41-48.

28. Li W, Chomel BB, Maruyama S, Guptil L, Sander A, Raoult D, Fournier PE: Multispacer typing to study the genotypic distribution of Bartonella henselae populations. J Clin Microbiol 2006, 44:2499-2506.

29. Li W, Raoult D, Fournier PE: Genetic diversity of Bartonella henselae in human infection detected with multispacer typing. Emerg Infect Dis 2007, 13:1178-1183.

30. Maiden MC, Bygraves JA, Feil E, Morelli G, Russell JE, Urwin R, Zhang Q, Zhou J, Zurth K, Caugant DA, et al: Multilocus sequence typing: a portable approach to the identification of clones within populations of pathogenic microorganisms. Proc Natl Acad Sci USA 1998, 95:3140-3145.

31. Maiden MC: Multilocus sequence typing of bacteria. Annu Rev Microbiol 2006, 60:561-588.

32. Turner KM, Feil EJ: The secret life of the multilocus sequence type. Int $J$ Antimicrob Agents 2007, 29:129-135.

33. Dorrell N, Hinchliffe SJ, Wren BW: Comparative phylogenomics of pathogenic bacteria by microarray analysis. Curr Opin Microbiol 2005, 8:620-626

34. Riess T, Andersson SG, Lupas A, Schaller M, Schafer A, Kyme P, Martin J, Walzlein $\mathrm{JH}$, Ehehalt $\mathrm{U}$, Lindroos $\mathrm{H}$, et al: Bartonella adhesin a mediates a proangiogenic host cell response. J Exp Med 2004, 200:1267-1278.

35. Riess T, Raddatz G, Linke D, Schafer A, Kempf VA: Analysis of Bartonella adhesin $A$ expression reveals differences between various $B$. henselae strains. Infect Immun 2007, 75:35-43.

36. Kaiser PO, Riess T, Wagner CL, Linke D, Lupas AN, Schwarz H, Raddatz G, Schafer A, Kempf VA: The head of Bartonella adhesin A is crucial for host cell interaction of Bartonella henselae. Cell Microbiol 2008, 10:2223-2234.

37. Zhang P, Chomel BB, Schau MK, Goo JS, Droz S, Kelminson KL, George SS, Lerche NW, Koehler JE: A family of variably expressed outer-membrane proteins (Vomp) mediates adhesion and autoaggregation in Bartonella quintana. Proc Natl Acad Sci USA 2004, 101:13630-13635.

38. Szacki J, Liro A: Movements of small mammals in the heterogenous landscape. Landscape Ecology 1991, 5:219-224

39. Corbet GB, Harris S: The Handbook of British Mammals Blackwell Scientific Publications, Oxford, Third 1991

40. Inoue K, Kabeya H, Kosoy MY, Bai Y, Smirnov G, McColl D, Artsob H, Maruyama S: Evolutional and geographical relationships of Bartonella grahamii isolates from wild rodents by multi-locus sequencing analysis. Microb Ecol 2009, 57:534-541.

41. Vitorino LR, Margos G, Feil EJ, Collares-Pereira M, Ze-Ze L, Kurtenbach K: Fine-scale phylogeographic structure of Borrelia lusitaniae revealed by multilocus sequence typing. PLoS One 2008, 3:e4002.

42. Jacob-Dubuisson F, El-Hamel C, Saint N, Guedin S, Willery E, Molle G, Locht C: Channel formation by FhaC, the outer membrane protein involved in the secretion of the Bordetella pertussis filamentous hemagglutinin. J Biol Chem 1999, 274:37731-37735.

43. Jacob-Dubuisson F, Kehoe B, Willery E, Reveneau N, Locht C, Relman DA: Molecular characterization of Bordetella bronchiseptica filamentous haemagglutinin and its secretion machinery. Microbiology 2000, 146(Pt 5):1211-1221.

44. Kimura A, Mountzouros KT, Relman DA, Falkow S, Cowell JL: Bordetella pertussis filamentous hemagglutinin: evaluation as a protective antigen and colonization factor in a mouse respiratory infection model. Infect Immun 1990, 58:7-16.

45. Relman DA, Domenighini M, Tuomanen E, Rappuoli R, Falkow S: Filamentous hemagglutinin of Bordetella pertussis: nucleotide sequence and crucial role in adherence. Proc Natl Acad Sci USA 1989, 86:2637-2641.

46. Cotter PA, Yuk MH, Mattoo S, Akerley BJ, Boschwitz J, Relman DA, Miller JF: Filamentous hemagglutinin of Bordetella bronchiseptica is required for efficient establishment of tracheal colonization. Infect Immun 1998, 66:5921-5929.
47. Abramson T, Kedem H, Relman DA: Proinflammatory and proapoptotic activities associated with Bordetella pertussis filamentous hemagglutinin. Infect Immun 2001, 69:2650-2658.

48. Inatsuka CS, Julio SM, Cotter PA: Bordetella filamentous hemagglutinin plays a critical role in immunomodulation, suggesting a mechanism for host specificity. Proc Natl Acad Sci USA 2005, 102:18578-18583.

49. Parkhill J, Sebaihia M, Preston A, Murphy LD, Thomson N, Harris DE, Holden MT, Churcher CM, Bentley SD, Mungall KL, et al: Comparative analysis of the genome sequences of Bordetella pertussis, Bordetella parapertussis and Bordetella bronchiseptica. Nat Genet 2003, 35:32-40.

50. Cummings CA, Brinig MM, Lepp PW, Pas van de S, Relman DA: Bordetella species are distinguished by patterns of substantial gene loss and host adaptation. J Bacteriol 2004, 186:1484-1492.

51. King AJ, van Gorkom T, Pennings JL, Heide van der HG, He Q, Diavatopoulos D, Heuvelman K, van Gent M, van Leeuwen K, Mooi FR: Comparative genomic profiling of Dutch clinical Bordetella pertussis isolates using DNA microarrays: identification of genes absent from epidemic strains. BMC Genomics 2008, 9:311.

52. Caro V, Hot D, Guigon G, Hubans C, Arrive M, Soubigou G, RenauldMongenie G, Antoine R, Locht C, Lemoine $Y$, Guiso N: Temporal analysis of French Bordetella pertussis isolates by comparative whole-genome hybridization. Microbes Infect 2006, 8:2228-2235.

53. Julio SM, Cotter PA: Characterization of the filamentous hemagglutininlike protein FhaS in Bordetella bronchiseptica. Infect Immun 2005, 73:4960-4971.

54. Kosoy MY, Regnery RL, Kosaya Ol, Childs JE: Experimental infection of cotton rats with three naturally occurring Bartonella species. J Wild Dis 1999, 35:275-284.

55. Schulein R, Dehio C: The VirB/VirD4 type IV secretion system of Bartonella is essential for establishing intraerythrocytic infection. Mol Microbiol 2002, 46:1053-1067.

56. Schulein R, Guye P, Rhomberg TA, Schmid MC, Schroder G, Vergunst AC, Carena I, Dehio C: A bipartite signal mediates the transfer of type IV secretion substrates of Bartonella henselae into human cells. Proc Natl Acad Sci USA 2005, 102:856-861.

57. Schmid MC, Scheidegger F, Dehio M, Balmelle-Devaux N, Schulein R, Guye P, Chennakesava CS, Biedermann B, Dehio C: A translocated bacterial protein protects vascular endothelial cells from apoptosis. PLoS Pathog 2006, 2:e115.

58. Kosoy MY, Saito EK, Green D, Marston EL, Jones DC, Childs JE: Experimental evidence of host specificity of Bartonella infection in rodents. Comp Immunol Microbiol Infect Dis 2000, 23:221-238.

59. Steppan S, Adkins R, Anderson J: Phylogeny and divergence-date estimates of rapid radiations in muroid rodents based on multiple nuclear genes. Syst Biol 2004, 53:533-553.

60. Birtles RJ, Raoult D: Comparison of partial citrate synthase gene (gltA) sequences for phylogenetic analysis of Bartonella species. Int J Syst Bacteriol 1996, 46:891-897.

61. Norman AF, Regnery R, Jameson P, Greene C, Krause DC: Differentiation of Bartonella-like isolates at the species level by PCR-restriction fragment length polymorphism in the citrate synthase gene. J Clin Microbiol 1995, 33:1797-1803.

62. Ewing B, Hillier L, Wendl MC, Green P: Base-calling of automated sequencer traces using phred. I. Accuracy assessment. Genome Res 1998, 8:175-185.

63. Ewing B, Green P: Base-calling of automated sequencer traces using phred. II. Error probabilities. Genome Res 1998, 8:186-194.

64. Gordon D, Abajian C, Green P: Consed: a graphical tool for sequence finishing. Genome Res 1998, 8:195-202.

65. Riess T, Dietrich F, Schmidt KV, Kaiser PO, Schwarz H, Schafer A, Kempf VA Analysis of a novel insect cell culture medium-based growth medium for Bartonella species. Appl Environ Microbiol 2008, 74:5224-5227.

66. Ehrenborg C, Wesslen L, Jakobson A, Friman G, Holmberg M: Sequence variation in the $\mathrm{ftsZ}$ gene of Bartonella henselae isolates and clinical samples. J Clin Microbiol 2000, 38:682-687.

doi:10.1186/1471-2164-11-152

Cite this article as: Berglund et al: Genome dynamics of Bartonella grahamii in micro-populations of woodland rodents. BMC Genomics 2010 11:152. 